\title{
An Investigation of the Nature and Functions of Exercises in Textbooks for Intensive Reading Course for English Majors
}

\author{
Wei Wu \\ School of Foreign Language, Guangzhou University, Guangzhou, Guangdong 510006, China \\ Email: christiew@126.com
}

\begin{abstract}
The qualification of the text exercises directly influences students' learning effect. This research is conducted reviewing and classifying the referred exercises in the English textbook, the author attempts to present the practical application of the exercises by means of investigation, exploratory research and interview with the nature and functions of the exercises as well. The research makes contributions to the deep understanding of the nature and functions of exercises in textbooks, serving as a reference for teachers to select and apply exercise types appropriately and effectively in their teaching practice. It can be of some significance in exercise design, evaluation, compiling and selection and in other areas of study within EFL.
\end{abstract}

Index Terms - exercises in textbooks, nature and functions of exercises, DE, ME, IE

It is widely recognised by many educators (Cheng,2002; Cunningsworth, 1995) that teaching efficiency can be improved by focusing on the teaching plan or syllabus design. Surprisingly, very few educators have discussed textbook exercises, and their relevance or impact to the overall learning experience.

Primary research, through interaction and observation, has revealed that textbook exercises receive little or no attention from either the student or teachers. Originally, textbook exercises are designed to ensure that the student has understood the textbook authors' understanding of teaching and language, therefore, they are essential to the overall language learning process. However, a review on those exercises within our domestic periodicals and English textbooks has revealed that the majority of research has only focused on a single aspect of the exercise (Luan, 2004; Hu, 2004). There are few studies that comprehensively discuss the nature and functions of exercises in English textbooks.

It is generally recognized that the goal of language teaching is to cultivate learners' communicative competence. Communicative competence is more than acquiring mastery of structure and form; it refers to the competence that enables us to convey and interpret messages and to negotiate meanings interpersonally within specific contexts (Hymes, 1972). One of the principle functions of textbook exercises is for students to self-test their mastery of recently learnt knowledge - in essence to cultivate students' communicative competence by means of providing them with more applicable exercises. There is however the debate as to which types of exercises can really facilitate learners' language learning and help them improve the communicative competence.

Therefore, the author will be focusing on those exercises used in the textbook with the aim to explore the nature and functions of learning exercises. Initially this article makes contributions, theoretically and practically, to the understanding of the nature and functions of exercises in textbooks, their design and intended use. Secondly, this research wishes to assist teachers with which types of exercises can be more appropriately and effectively employed in their classroom teaching practice. This research should help teachers either select and apply the exercises in a more consistent manner, or prepare and implement classroom activities. In both instances this research should enable students to make better use of the exercises and improve their communicative learning. Finally, these findings should allow readers greater meaningful evaluation of exercises and inspiration for their use.

\section{RESEARCH BACKGROUND}

\section{A. The Input Hypothesis}

The Input Hypothesis assumes that humans acquire language only by understanding messages, or by receiving “comprehensible input" (Krashen, 1985, p. 2). In other words, the language which learners are exposed to should be just far enough beyond their current competence that they can understand most of it but still be challenged to make progress.

We define good input as language that is comprehensible and that the learner has to understand it in order to get a meaningful message. "Learners should be exposed to an abundance of good input and given ample opportunities to process it for form and meaning" (Rubio, Passey \& Campbell, 2004, p. 161).

In addition to course book texts, exercises as well direct language exposure to the students and can provide great language learning opportunity. According to the Input Hypothesis, the exercises should be designed for 'comprehensible input'. Namely, based on students' current level of competence, the difficulty and quality of the exercises should, in 
many cases, even go slightly beyond their current competence. A drastic deviation from proper difficulty would undermine both students' competence and their language acquiring process. Thus, the exercises should be suitably designed not only for the students' current level, but also form part of the teachers' overall teaching program. In the Chinese ELT context, to design good input exercises for textbooks is very important, but it is still controversial as to what consists the basic criteria to judge the quality of the exercises.

\section{B. The Output Hypothesis}

Coined by Merrill Swain (1993), the term "Output Hypothesis" reveals the important notion, that the importance of output to learning could be that output pushes learners to process language more deeply (with more mental effort) than input does. While focusing on output, we may be focusing on ways in which learners can play more active and responsible roles in their learning. If learners fail to speak fluently even though they are given enough good input, the reason is that output activities are not enough; learners are not 'being pushed' in the language output activities. For Swain, 'being pushed' in output is a concept parallel to that of the ' $\mathrm{i}+1$ ' comprehensible input (Swain, 1985,p248). She also argues that production may encourage learners to move "from semantic processing to syntactic processing (ibid: 249)". That is, to force the learners to pay attention to the means of expression. Comprehensible output is necessary especially in classroom interaction, after the teacher has initiated negotiation. If the student responds to the teacher's initiation, he has to make necessary adjustments, such as simplification, elaboration, modifying tense or collocation, to his original utterance and make his output more accurate and understandable. This will help the student test his/her hypothesis about the target language and help the teacher evaluate whether others could accept the learner's modified output.

When discussing language input and output, we are actually approaching language acquisition from different perspectives. It cannot be established that language input and output overwhelms one another, as both of them are equally important to SLA.

There are various exercises designed for teachers to improve students' speaking abilities, which focus on the communicative competence and interaction among different people in the real world.

The following output activities are both communicative and have distinct unique characteristics.

A: Structured output activities

Two common kinds of structured output are blank-filling and jigsaw activities. In both types of these activities, students complete a task by obtaining missing information - a feature the activities have in common with real communication. However, blank-filling and jigsaw activities also allow practice on specific items of language, which in essence make them more like drills than communication.

B: Communicative output activities

Communicative output activities allow students to practise using the language they know in situations with real settings. In these activities, students must work together to develop a plan, resolve a problem, or complete a task. The most common types of communicative output activities are role-plays and discussions (Littlewood, 1981).

\section{Evaluation of the Exercise/Task}

Evaluation of the exercise/task helps teachers to identify particular strengths and weaknesses of exercises in the textbooks already in use so that optimum use can be made of their strong points, while their weaker areas can be strengthened through adaptation. In other cases, teachers need to evaluate materials in order to choose the ones they consider to be most appropriate to their specific teaching contexts. Under such circumstances, "evaluation is a mater of judging the fitness of something for a particular purpose"(Hutchinson, \&Waters, 1987,p96). In his paper on task design, Candlin (1987) suggests that task evaluation should cover three broad areas, i.e. 'problematicity', 'implementability', and 'combinability'. Under the rubric of 'problematicity' one would consider the extent to which it is diagnostic or explanatory, whether it provides monitoring and feedback, and whether it can be used as a basis for future action. 'Implementability' leads one to a consideration of the resources required, the organizational and management complexity, and the adaptability of the task. Finally, 'combinability' requires us to consider the extent to which the task can be sequenced and integrated with other tasks (Luanluan, 2004,p4).

\section{Discrete Point Testing and Integrative Testing}

When we discuss textbook exercises, we are referring to tools that are used for testing students' mastery of knowledge; therefore it is unavoidable for one not to mention language testing. Exercises are actually informal tests to measure students' abilities or knowledge in an overall proficiency of a language. The controversy between discrete point and integrative testing methods is still open for discussion.

The proponents for the discrete point testing, believe that language can be broken down into its component parts. The test can then measure these discrete points of language by adequate sampling of these units and achieve validity. In other words, the discrete points of language can be learnt and tested. As a result of this school of thought, there are some test types designed for measuring how students master the discrete language points, such as single word/phrase blank-filling, and multiple choice on the usage of words or grammar.

However, this approach is criticized by other linguists who argued that language competence is a unified set of interacting abilities that cannot be separated apart and tested adequately. In their opinions, language is regarded as an 
integrative system, each component of it cannot be divided into pieces and tested; only when we treat it as a whole, can it be tested. There are some test types designed for this rationale based on the concepts of communicative competence which emphasizes on the integrative competence of the knowledge. Dictation is a typically integrative test which can measure the integrative competence of students.

As both testing methods are still in open debate, one will discover that, there are discrete and integrative exercises within textbooks. The purpose of this research is not to debate which approach is better for testing, but to simply acknowledge that both discrete and integrative terms are used. The author will therefore use both test methods as a classification and analysis category, for the exercise types reviewed in this article.

\section{E. The Present Research concerning English Textbooks Exercises}

Some domestic experts and educators have done some research on the exercises in English textbooks. According to Xia (2002, p. 148), the quality of modern exercises should be judged by applying cognitive theories and the communicative rules. Standards according to the cognitive psychology are: the exercises should provide the audio, visual stimuli; The exercises should transfer human's cognitive potential, like experiences, mentality, emotion, and creativity; The exercises should provide a variety of discourses and activities to cater for the different personalities, habits, and learning styles of students etc. The types of exercises could be different, such as: the warm-up activity, leading-in activity, ice-breaking activity, brain-storming activity, gap activity, topic/theme/content-based discussion, situational activity, problem-based activity, case-studies, story-telling etc. The variety and diversity of exercises could provide students with a wide scope of knowledge practice. In all, in the modern EFL context, the design of exercises should show more concern with the needs and abilities of human beings, the exercises may be more"humanistic", the humanistic exercises are said to have the following characteristics: 1) Emphasis on personal experience and group experience.2) Teachers' genuine intervention in learning: students are trying to express meanings they cannot express. 3) Special protection of learners' curiosity. 4) Teachers are genuinely interested in students' replies. 5) Encouraging students to bring themselves physically to class (Arnold, 1999:199-200). In practice, Chang Xinping (Chang, 2007,p.37-56) has done some experiments to apply humanism in her English teaching. Her experimental report indicated students' abilities to use the language, to work with their classmates, and to present themselves in public places were improved greatly after she had employed special humanistic teaching style with the specially-designed humanistic exercises and activities. However, the present EFL learning in China is still test-driven, in other words, examinations still dominate the teaching, most tests and examinations are still designed to evaluate the test takers' grammatical competence without testing students' pragmatic competence. Such a trend of test-oriented English learning and teaching really influences the design of textbooks exercises and activities, most of the exercises may succeed in helping students pass the exams but fail to foster their abilities to use language in real life. But, what is to be tested and what exercise types are employed in textbooks are of great significance to learners' communicative competence development.

\section{RESEARCH QUESTIONS}

The present research attempts to answer the following questions:

1) What are the main types of exercises in the referred English textbooks?

2) What are the nature and functions of the exercises in the different categories?

3) Which types of exercises can be considered as facilitating exercises?

\section{METHODS AND PROCEDURES}

This research covers three parts. Briefly those parts are:

1) Part one investigated the exercise types in the referred textbooks.

2) Part two is a qualitative analysis of different types of exercises, using the criteria explained in Point 4:3).

3) Part three is the interviews. In this study investigations were the main research instruments, while interviews served as indispensable supplementary tools.

These methods completed with each other in this research.

\section{INVESTIGATION INTO THE EXERCISE TYPES IN THE REFERRED TEXTBOOKS FOR ANALYSIS}

\section{A. Research Aims}

This investigation will explore the exercise types employed in the textbooks for the intensive reading course. From the investigation, the author attempts to probe the exercise types and their nature and functions, which the learners have been exposed.

\section{B. The Textbooks for Analysis}

This research investigates the exercise types employed in the widely used textbooks for English-majors in Guangzhou University. The author chose An Integrated English Course Book (ed. He Zhaoxiong, published in 2005 by Shanghai Foreign Language Education Press) as the basis for the analysis of the exercises. As this series of textbook is 
the main-stay of teaching material for the intensive reading course, it is the author's intention to review the exercises within referred book and determine their validity and applicability to communicative learning. With aims to improve students' comprehensive abilities including listening, speaking, reading, and writing, this series of textbooks claim a full range of exercises that are varied and typical enough for the research.

Since the textbook series have four textbooks, all following the same publisher design principles, the author thought it best to test the first and the last of the books in referred series. It is the hope of the author to demonstrate the change in learning exercise utilization and its significance as the student progresses through the language course. Therefore for the purpose of this thesis the author will focus on book I and IV of this series.

Since the author is analysing both the first (beginner) and the last (expert) book in the series, this research will span both grade one and grade two English-major undergraduates in Guangzhou University.

\section{Criteria for the Classification of $D E$ and $M E$}

The textbook exercises are classified by their nature and functions into three categories: DE, ME and IE. When referring to DE, we mean those exercises which orient at discrete linguistic knowledge learning or discrete skill training. With ME, we refer to exercises which orient at meaning conveyance or interactive communication. Finally, IE refers to those integrative exercises which contain both the characteristics of DE and ME by orienting at integrative linguistic skills training.

The different nature and functions of DE and ME allow the textbook exercise classification to become objective. These findings are summarized in the following table A, which will be explained in detail. Each criterion will be explained and used for the analyses undertaken on the textbook exercises, using the predefined categorisation method for DE, ME and IE nature and functions.

TABLE A

CRITERIA FOR THE CLASSIFICATION OF DE AND ME

\begin{tabular}{|ll|}
\hline (1) & Whether the exercises are contextulized. \\
\hline (2) & Whether the exercises are meaning-oriented with the aim to convey the meaning. \\
\hline (3) & Whether the exercises are designed with information gaps, which require students to complete from other \\
sources or opinions.
\end{tabular}

Each criterion is explained thoroughly below, with recommendations as how to judge whether the exercise is DE or ME.

A. Whether the exercises are contextulized.

The word "contextulized"refers to the existing nature what comes before and after a word, phrase, statement, etc. helping to fix the meaning (Oxford Advanced Learners'Dictionary 1988:250). "Try to give language some context so that items aren't just a string of unrelated language samples "(Brown, 1994,p.271). If the exercises are contextulized, students are put into real situations or an imitated real situation to complete the task. The real situation originates from real life, which provides students with specific circumstances; thus, students can connect the discrete linguistic knowledge and automatically know how to use them in the given situation appropriately. However, it should be discerned that"students often make errors because of a pattern that was rotely memorized in a drill but not properly contextualized"(Ibid: 215).

We can easily distinguish an exercise which is contextulized in nature in comparison to the pattern exercise. Thus, if the exercises are contextulized, they are ME in nature; if the exercises are decontextulized, they are DE in nature.

B. Whether the exercises are meaning-oriented with the aim to convey the meaning.

Meaning-orientation is an important ME character. Only when the meaning conveyance exists, then communication happens, which stresses that rules should serve the purpose of presenting meaning. If the exercises are not designed for conveying the meaning, they are definitely not ME.

C. Whether the exercises are designed with an information gap.

An information gap should require a student to fill in the missing information — the "gap"from other sources or from other opinions. When one person in an exchange knows something that the other does not, then an information gap exists. In the process of filling in the "gap", the students need to discuss in pairs or groups to transfer or negotiate meaning. To be specific, take one exercise for example: if two students in the conversation know the day is Tuesday while the exercise requires students to practice the sentence pattern"What day is today?", the answer is obviously "Tuesday". This conversation is not 'real communication', because both students know the answer and there is no information gap. This exercise is not communicative, and therefore definitely not ME.

D. Whether the exercises can be finished by students with free choice.

The free choice criterion means the language form used by the speakers is not under some control. In communication, people have a choice of what they will say and how they will say it. People can make their own choice freely and casually. In this manner, unforeseen elements are included in the communication. In classroom communication, students do not know the answer and have their own feedback to the command. ME exercises should contain unforeseen elements and allow students greater latitude to experiment and trial their communicative language skills. 
If the exercise is tightly controlled so that students can only say something in one way, then the students have no choice and the exchange is not communicative (Larsen-Freeman, 2000, p. 129). In this instance, these exercises are DE in nature. For example, if students are given a topic to discuss jobs they will choose to do in the future, they can freely express their opinions productively and receptively without a controlled situation, making this exercise ME.

E. Whether the exercises are based on the authentic, natural language data.

Authentic language describes how real-life materials are used as the basis of teaching and learning. Larsen-Freeman (2000) defined authentic language as: language which is used in a real context.

One essential way to improve students' comprehensive abilities is to provide them with materials that come from real life with no addition or deletion, or even omission of language difficult point (Xu, 2000,p.62). Thus, if the exercises are based on the authentic, natural language data, they are ME; if not, they are DE.

Integrative exercises (characterized by both DE and ME) emphasize not only discrete linguistic knowledge learning or discrete skill training, but also meaning conveyance or interactive communication. To this end the author only discovered a small amount of IE exercises in the pre-selected textbooks.

\section{INTERVIEWS}

\section{A. Aims}

The interviews were carried out after the investigation. Since the investigation gave a general description of exercise types by their nature and functions, the interviews were conducted to help the researcher to collect more relevant data about the opinions of both teachers and students to the exercise types in the textbooks.

\section{B. Subjects}

Since the interview survey is only a small part of the whole project and that it is exploratory in nature, a relatively small sample was chosen. Convenience sampling methodology was used.

The subjects were obtained on a voluntary basis from the English-major undergraduates student body who are using An Integrated English Course Book as textbooks in grade one and grade two. Teachers who are giving lectures based on these textbooks were also interviewed.

The ten English teachers selected, have been engaged in English-major teaching for no less than three years. This provides a wealth of reference for this thesis.

Twenty students were chosen based on referrals from the teachers, in Guangzhou University. Ten of them are female with five in grade one and five in grade two, and the remainder male with five in grade one and five in grade two also. In short, ten of the sample are at a high proficiency level whilst the remainder are at a low proficiency level.

\section{Interview Questions}

The author chose semi-structured interviews with open-ended questions. The interview questions are concerned with the variety of exercise types, DE, ME and IE, used to facilitate exercises in learning. It should be noted that, before the interviews, the finalized eleven exercise types of DE, ME and IE (listed below) were mixed together and were presented to teachers and students. Pre-instruction or guidance with reference to the concepts of DE, ME and IE was provided to teachers and students only when mentioning question three.

Questions to teachers and students are different, because they would hold various points of view regarding the exercise types, predominantly based upon their knowledge and expectations of the textbook exercises.

The questions were presented to teachers and students in English, because both teachers and students can express in English well in the asking-and-answering process.

The questions to teachers are listed as follows:

Q1: Do you think there is a wide variety of exercise types in your textbook?

Q2: How do you handle different exercise types?(with the table B provided)

Q3: Which types of exercises are the facilitating ones?

The questions to students are listed as follows:

Q1: Do you think there is a wide variety of exercise types in your textbook?

Q2: How do your teachers handle different exercise types? (with the table B provided)

Q3: Which types of exercises are more important in your learning? 
TABLE B

ELEVEN EXERCISE TYPES IN THE REFERRED TEXTBOOKS

\begin{tabular}{|ll|}
\hline (1) & Single word/phrase blank-filling orienting at mastering usages of discrete words/phrases or grammatical rules. \\
\hline (2) & Vocabulary exercises focusing on distinguishing among the synonyms or antonyms. \\
\hline (3) & Translating sentences into English with given words or phrases which focus on mastering usages of isolated words or phrases. \\
\hline (4) & Oral activities focus on role playing for meaning conveyance and interactive communication. \\
\hline (5) & Oral activities on discussing questions or topics orienting at meaning conveyance and interactive communication. \\
\hline (6) & Oral activities on debate orienting at meaning conveyance and interactive communication. \\
\hline (7) & Dictation exercises orienting at interpreting meaning and organizing the passage. \\
\hline (8) & Exercises on listening comprehension that demand comprehensive listening abilities. \\
\hline (9) & Paraphrasing words or part of the sentence which focus on the restating ability to convey the similar meaning. \\
\hline (10) & Single word/phrase blank-filling orienting at training reading comprehension with integrative linguistic abilities. \\
\hline (11) & Composition writing orienting at training writing abilities with integrative linguistic abilities. \\
\hline
\end{tabular}

\section{RESULTS}

\section{A. Results of the Classification of the Exercise Types}

The results of the classification of exercise types in textbooks are presented below. Three types of exercises are established as being in the referred textbooks, when using the nature and functions of exercises as a measurement tool.

The first type of textbook exercise orients toward discrete linguistic knowledge learning or discrete skill training(DE). The following detailed exercises with their requirements can be classified into this category.

1) Single word/phrase blank-filling orienting at mastering usages of discrete words/phrases or grammatical rules.

2) Vocabulary exercises focusing on distinguishing among the synonyms or antonyms.

3) Translating sentences into English with given words or phrases which focus on mastering usages of isolated words or phrases.

The second type of textbook exercise orients toward meaning conveyance or interactive communication (ME). The following example exercises with their requirements can be classified into this category.

1) Oral activities focused on role playing for meaning conveyance and interactive communication.

2) Oral activities on discussing questions or topics orienting at meaning conveyance and interactive communication.

3) Oral activities on debate orienting at meaning conveyance and interactive communication.

4) Dictation exercises orienting at interpreting meaning and organizing the passage.

5) Exercises on listening comprehension that demand comprehensive listening abilities.

6) Paraphrasing words or part of the sentence which focus on the restating ability to convey the similar meaning.

The third type of textbook exercises is IE. IE combines the nature of both DE and ME, in other words, they are characterized by both DE and ME. This type of exercises focuses not only on discrete linguistic knowledge learning or discrete skill training but also on the meaning conveyance or interactive communication competence training. This means that IE demands integrative linguistic abilities from students. The following sample exercises with their requirements can be classified into this category.

1) Single word /phrase blank-filling orienting at training reading comprehension with integrative linguistic abilities.

2) Composition writing orienting at training writing abilities with integrative linguistic abilities.

\section{B. Results of the Data on Exercise Types}

According to the survey and calculations, there is a total number of 304 exercise items involved in An Integrated English Course Book I. Among them, 179 items are DE, representing a percentage of 58.9\%, compared with 89 items of ME, accounting for $29.3 \%$ of the total number. 36 items are IE, representing a percentage of $11.8 \%$.

As far as Book IV is concerned, it contains 272 exercise items, with 158 items of DE and 81 items of ME, accounting for $58.1 \%$ and $29.8 \%$ respectively. 33 items are IE, representing a percentage of $12.1 \%$.

These results indicate that DE plays a dominant role in the textbooks while ME and IE play facilitating roles. 


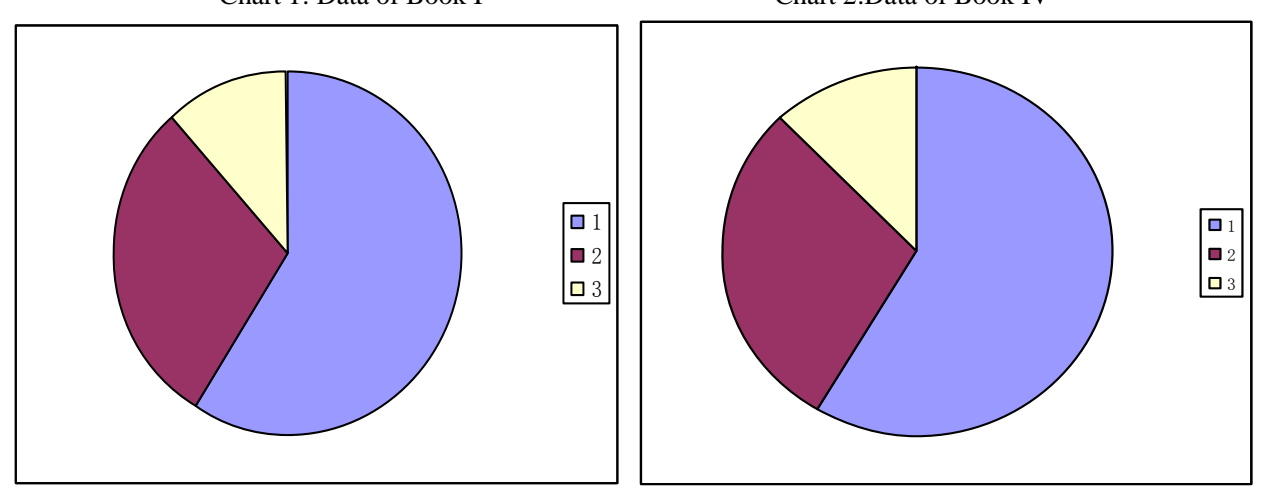

figure 1 is the ratio of $\mathrm{DE}$

figure 2 is the ratio of $\mathrm{ME}$

figure 3 is the ratio of $\mathrm{IE}$

\section{Results of the Interviews}

\section{1) Feedback from Teachers}

Feedback from the teacher interviews makes it obvious that the current exercises in the referred textbooks are not satisfactory as a whole. There are some aspects of the findings which have to be addressed by future publishers.

In response to the first question, all teachers think that students are not exposed to a wide variety of exercises in textbooks. There is the belief that exercise types are so limited and poor, that students can only benefit from some improved exercise types in both grade one and grade two. It was noted that, even the design of the exercises after each unit is the same. Therefore, gradually as students progress through their studies, the exercises would offer less challenge and learning.

Some of the exercises are either too easy or too difficult and not designed well for the current level of students. Most exercises adapted from the texts are too academic and complicatedly structured, lacking in any authentic and natural language that may come from real life. When students make use of the sentences from the textbook exercises during practice, they usually do not know how to use the language appropriately and in what situation. Their answers reflect the fact that to design exercises with more variety and diversity, corresponding with students' current level and getting close to the reality with real language are what compilers need to consider for their future publications. The exercise types need to undergo reform as well as the textbooks. It is of little use that many textbooks are adapted without any reforms to the exercises.

Within the second question, the author focused on textbook exercise item type (see table B). With respect to item type (1) to (3) (gap; vocabulary; translation), all teachers would make comments and explain difficult language phraseology to students, and then leave some time for answering students' questions. They would not spend much time on these three types of exercise items. Items (4) to (6) are the oral activities, all of them would spend one third of the exercise time to develop students' oral abilities. In this part, teachers act as the assistants in helping students to solve problems; act as the participants to join the heated discussions; act as the guides to organize each group and make sure the whole class is under control. All teachers interviewed enjoy this part, in their opinions, students become more active and the atmosphere in the class is more vivid and relaxed. One teacher said that students are engaged in the oral activities on their own initiatives. In order to play the roles, they discuss the plots, assign the roles, have a rehearsal and present the play only within fifteen or twenty minutes, with the result appearing as if much more time was spent in preparation. Items (7) and (8) are listening practice. Five teachers play the recorder and check the answers from students. Another five teachers leave it as homework for students to finish after class. They give students the answers as reference but ask students to copy the tape beforehand. Item (9) is a paraphrasing exercise. All the teachers would paraphrase the sentences in this exercise when they explain the texts. Item (10) is the cloze exercise type. Six of the teachers would explain each blank thoroughly, while the remaining four teachers just answer the questions from students. It is felt that the questions are the most difficult unsolved points for most students, and that this is the best way to find out students' questions. The last item is composition. Three teachers would ask students to finish it after class. Seven teachers would ask students to make an outline within ten minutes in the class, and make some comments on the writing skills or topics of the composition.

The reactions of the teachers reflect that each teacher has his own understanding of the exercises, thus, they would handle the exercises varyingly. However, some handlings are similar: all teachers would not use much time on items (1) to (3) which are DE in nature. This reveals that teachers would not pay much attention on the discrete linguistic points. Meanwhile, oral activities take up much time allowing students to practice their speaking abilities. Oral activities are seen as a climax in the class because of the vivid atmosphere and students' active participation. This reveals that teachers attach much importance to cultivation of students' speaking abilities, meaning conveyance and interactive communication. As for other exercise types, teachers would put either more or less emphases on the specific exercises, thus, the implementations vary. Briefly speaking, teachers actually put emphases on those exercises which are 
considered to be the weakness of their students.

To answer the third question, the concepts of DE, ME and IE had been explained to teachers beforehand. Generally, all teachers thought DE, ME and IE can be considered facilitating. However, the teaching effect is different. DE does aid second language (L2) acquisition which is essential for the mastery of a language. The more we can find out about how grammar and vocabulary are learned and used, the better positioned we will be to teach it effectively. ME yields a notable teaching effect in teaching and learning for communicative competence. It was also noted that by combining the characteristics of DE and ME, IE assists students with the development of their integrative language abilities.

Seven teachers consider ME as more facilitating exercises, among them, five teachers also consider IE as more facilitating ones. The rest three teachers regard DE as more facilitating ones.

To summarize, ME and IE were considered as more facilitating exercises in language teaching and development for communicative competence in comparison to DE. Teachers interviewed pointed out that there are more concrete exercises of DE and less ME exercises in the textbooks, since most teachers regard ME exercises as more facilitating ones, with the aim of improving students' communicative competence, they hope that compilers should provide more ME exercises for teachers and students.

The problems noted above reflect that exercises should be improved not only to meet students' needs in learning, but also to meet the demand of modern English teaching - to cultivate students' communicative competence. It was realized that DE or ME, even IE should be better adapted to offer more relevant textbook exercises - this requires greater contributions and input from teachers to drive the correct textbook exercise reform.

\section{2) Feedback from Students}

Unsurprisingly, students' feedback from the interview, clearly demonstrates differing views on the questions and functions of textbook exercises. There are some aspects of the findings which will have to be addressed later in this article.

The students' answers reflect that various teachers would handle the textbook exercises differently. The interview illustrates that all students think their teachers use less time for items(1) to(3) - which are the exercises of DE, but use more time for items (4) to (6) - which are the exercises of ME. It reveals that teachers put much emphasis on developing students' communicative competence by improving students' speaking abilities. The discrete words/phrases and grammatical rules usually take place during the comment and answering of student questions - both of which take up a relatively little time. Generally these answers align with the teachers' opinions.

The concepts of DE, ME and IE had been explained to students beforehand, so that they could competently respond to question three. Students responded similarly "All of the exercises are important in my learning". Twelve students regarded ME as the more important exercises, among them, ten students also regarded IE as the more important exercises. Surprisingly the remaining eight students regarded DE as most important.

Actually, it is hard to identify which types of exercises can be considered as the 'more important ones', because each exercise type is designed for the specific purpose to develop students' linguistic competence. The emphasis of each exercise type is on different aspects of language abilities and acquisition. In addition, various students hold differing attitudes toward this question. However, the results indicate that most of the interviewed students regarded ME and IE as the more important exercises. In their opinions, ME focuses on practicing their speaking and listening abilities, so students can make progress in communicating. IE is to develop the students' integrative abilities concerning all aspects of language. Therefore, most of the students through this commentary, regarded ME and IE as the more important exercises, but also recognized that the functions of DE are also necessary for a 'holistic' communicative competence.

\section{SOME PROBLEMS OF TeXtBoOK EXERCISES}

During the investigation, some problems were identified to still exist with the textbook exercises:

1) Scarcity of exercise types

By means of analysing the exercise types in the referred textbooks, the author has found that totally there are eleven types of exercises available. There is not a variety of exercise types in the textbooks. The exercise types are too limited and very simple in forms. The exercises do not provide enough content or context for students to learn. If students are not exposed to sufficient exercise types, what provide for them are merely several types of exercises, and there is no or little discourse level training suitable for students' current level. Thus, students may get used to completing the fixed exercise types without being introduced to other types of exercises, which restrict them in a narrow scope of knowledge practice. Gradually, they may cease progress in acquiring the knowledge. To some degree, the scarcity of exercise types can hinder students' learning process.

2) Deviated input of exercise types

Another finding from the investigation is that some exercise types have close connection with the texts but deviate from the real life. Recent research on the discourse types employed within college textbooks indicate that 95.25 percent of discourse types employed in intensive textbooks are of an academic nature (Dong, 2007,p.53). Also of these discourse types, most are expositions and argumentations. Formal and precise as the language in these academic passages is, the language of these exercises is deviated from the reality. Now that students learn to use the target language mainly through learning textbooks, the authenticity of the language in textbooks is crucial to the students' final achievement. Authentic materials enable students to learn real English instead of the English contrived by their 
teachers. If students are expected to be exposed to more authentic materials, the communicative competence will be developed. Thus, although the exercises can test the degree of how students grasp the knowledge from texts, they fail to facilitate appropriate language use for daily communication.

\section{SUMMARY OF THE PRESENT STUDY}

This thesis has explored the main types, nature and functions of textbook exercises utilized on the intensive reading course for English-major undergraduates in Guangzhou University. Based on the research results described in the previous chapters, possible responses to the research questions are given below.

1) What are the main types of exercises in the referred English textbooks?

The exercises used in the researched textbooks were classified into three categories according to their nature and functions.

The first category of textbook exercises focus on discrete linguistic knowledge learning or discrete skill training (DE). DE example exercise types are: (1) single word or phrase blank-filling which concentrate on mastering usages of discrete words/phrases or grammatical rules; (2) vocabulary exercises focusing on distinguishing the differences between synonyms or antonyms; (3) translating sentences into English with given words or phrases which focus on mastering usages of isolated words or phrases.

The second category of textbook exercise promotes meaning conveyance or interactive communication (ME). ME example exercise types are: (1) oral activities requiring role playing and interactive communication with the intent of meaning conveyance; (2) oral activities that discuss questions or topics; (3)open oral debates; (4)dictation exercises focusing on interpreting meaning and organizing the passage; (5)exercises of listening comprehension that demand comprehensive listening abilities; (6) paraphrasing words or part of the sentence enabling ones' restating ability to convey similar meaning differently.

The third exercise category is known as integrative exercises (IE). IE embodies both the nature and functions of DE and ME. IE enables integrative linguistic learning. The primary examples of IE exercises are:

(1) single word or phrase blank-filling(cloze) designed to improve reading comprehension with integrative linguistic abilities;

(2) composition writing with topics or titles with integrative linguistic abilities.

As listed above, there are eleven main types of textbook exercises that can be categorized into either DE, ME or IE. All exercises are designed to improve students' integrative abilities in listening, speaking, reading and writing.

The interview results reflect that the diversity and variety of textbook exercise types are not adequate. Therefore, the author believes students are not exposed to a sufficient variety and diversity of exercise types in their learning. Without sufficient input from a wide variety of textbook exercise types, students could find it difficult to use the learned language in 'unfamiliar situations'. This lack of 'real world' exercise exposure, will undoubtedly hinder students' communicative competence development.

Coupled with students' exposure problems, many textbook exercises can be considered either too complicated or easy, and therefore require teachers' intervention or adaptation to make them suitable. Some textbook exercises use far too much academic language that many students will never use in the real world. Such problems as these, must be addressed in future publications.

2) What are the nature and functions of the exercises in the different categories?

By studying and analysing the unique requirements; settings; nature and functions of specific exercises, the author has determined that those textbook exercises employed by Guangzhou University are DE ,ME and IE in nature. Simply these exercises are:

(1) Exercises which focus on discrete linguistic knowledge learning or discrete skill training (DE);

(2) Exercises which enable meaning conveyance or interactive communication (ME);

(3) Integrative exercises contain the characteristics of $\mathrm{DE}$ and $\mathrm{ME}$ enabling integrative linguistic knowledge acquisition (IE).

In brief, the author's investigation illustrates that there are more DE rather than ME textbook exercises in those books reviewed. It is from this analysis that the author has concluded that DE plays a major role while ME offers a more facilitative role. Both ME and DE, considerably overshadow the IE teaching content, which accounts for a relatively small amount of those textbook exercises reviewed.

Surprisingly, the results of the interviews indicate that too much attention is presently placed on training students' abilities on meaning conveyance or interactive communication, which is probably the most effective means for improving communicative competence.

In an "integrative-sociolinguistic" era with its emphasis on communication, authenticity and context, communicative competence remains the focus of the linguists and researchers. The ultimate goal of language teaching is to cultivate learners' communicative competence. To achieve this goal, the modern teaching approach employs any means to foster students' communicative competence, differing greatly from the more traditional teaching methods, which tended to focus on the formal aspects of language - grammar, vocabulary, and pronunciation (Brown, 1994:265). Meanwhile, the exercises underlying the modern teaching approach should be designed to measure a much broader range of language abilities, including knowledge of cohesion, functions, and sociolinguistic appropriateness, ME exercises with the similar 
functions can be used to test the abilities mentioned.

In classroom, although ME accounts for a relatively small part compared with DE, teachers spend much time in handling ME, students become more active in doing ME. Therefore, to meet the demands of the modern English teaching, we need more ME textbook exercises as the teaching tools-all designed with the main aim of improving the communicative competence.

However, one possible reason for compilers' designing more DE exercises may lie in the fact that discrete linguistic knowledge learning or discrete skill training is essential for healthy and meaningful linguistic development. Rich vocabulary and grammatical knowledge with excellent reading and writing are fundamental linguistic competences necessary for fluent interaction and social communication. As these linguistic competences are indispensable, it can only be surmised that DE textbook exercises which constitute the majority in the exercises are a necessary and fundamental tool in language teaching. However, why do DE exercises not yield notable teaching effect? The principal problem with DE teaching is that it takes considerably longer, harder, and slower than its ME counterpart. Due to the nature of DE exercises they are considered by students to be less engaging, and more 'boring'. It is a fine balancing act for teachers to ensure effective communicative competence development but not at the expense of fundamental lexical language understanding. In other words, we can neither overemphasize the functions of ME nor underestimate the functions of DE.

3) Which types of exercises can be considered as facilitating exercises?

In practice, $\mathrm{ME}$ textbook exercises are more effective 'communicative capability' facilitators in comparison to $\mathrm{DE}$ textbook exercises. ME exercises provide students with real situation, which means contextulized, students could connect what they learnt naturally and appropriately. Thus, ME exercises can be considered as the most facilitating exercises for their notable teaching effects.

IE exercise type is a combination of the best elements of both ME and DE. It has been proven to effectively facilitate language learning as well, however, it currently only represents a minor percentage of textbook exercises available.

\section{REFERENCES}

[1] Arnord, J. (1999). Affect in Language Learning. Cambridge: Cambridge University Press.

[2] Brown, H.D. (1994). Principles of Language Learning and Teaching. Beijing: Foreign Language Teaching and Research Press.

[3] Canale, M. and Swain, M. (1980). Theoretical bases of communicative approaches to second language teaching and testing. Applied Linguistics , 1, 1-47

[4] Candlin, C. (1987). 'Toward Task-based Learning.' In Language Learning Tasks, ed.. Englewood Cliffs NJ: Prentice Hall.

[5] Celce-Murcia, M. (2001). Teaching English as a Second or Foreign Language. Boston: Heinle \& Heinle Publishers.

[6] Chang Xinping. (2007). Integration of Humanism in EFL Teaching-A Teacher's Explorations. Promenades in Language, 1, 37-56

[7] Cheng Xiaotang. (2002). The Analysis and Design of the English Textbook. Beijing: Foreign Language Teaching and Research Press.

[8] Cunningsworth, A. (1995). Choosing Your Coursebook. Oxford/Shanghai: Macmillan Publishers Limited/Shanghai Foreign Language Education Press.

[9] Dong, J.X. (2007). Chinese EFL Learners' Exposure to Discourse Types And Their Pragmatic Competence Development. Unpublished MA thesis, Zhongshan University

[10] He Zhaoxiong. ed. (2005). An Integrated English Course. Shanghai: Shanghai Foreign Language Education Press.

[11] Hu, X.M. (2004). Oral Practice Design and Learners' Interest. Unpublished MA thesis, Jianxing Normal University.

[12] Hutchinson, \& Waters, (1987). English for Specific Purposes. Shanghai: Shanghai Foreign Language.

[13] Hymes, D. (1972). On communicative competence In Pride, T.B \& Holmes.J. (Eds) Sociolinguistics, 269-293, Harmondsworth: Penguin.

[14] Krashen, S. D. (1985). The Input Hypothesis: Issues and Implications. Longman Inc., New York.

[15] Larsen-Freeman, D. (2000). Techniques and Principles in Language Teaching. Oxford: Oxford University Press.

[16] Littlewood, W. (1981). Communicative Language Teaching. Cambridge: Cambridge University Press.

[17] Luan, L. (2004). The Design of the Intensive Reading Exercises under the Task-based Teaching Theory. Unpublished PhD thesis, Northwestern Polytechical University.

[18] Oller, J. W. (1976). A Program for Language Testing Research. Language Learning, Special Issue Number, 4,141-165

[19] Oller, J. W. (1979). Language Tests at School: A Pragmatic Approach. London: Longman Group Limited.

[20] Oxford Advanced Learners' Dictionary of Current English with Chinese Translation. (1988). Oxford: Oxford University Press.

[21] Rubio, F. \& Passey, A. \& Campbell, S. (2004). Grammar in Disguise: the Hidden Agenda of Communicative Language Teaching Textbooks. RAEL: revista electrónica de lingüística aplicada,3, 158-176

[22] Swain, M. (1985). Communicative competence: Some role of comprehensible input and comprehensible output in its development. In S.M. Gass \& C.G. Madden (Eds) Input in Second Language acquisition, 235-253, Rowley, MA: Newbury House.

[23] Swain, M. (1993). The Output hypothesis: Just Speaking and Writing aren't Enough. Canadian Modern Language Review, $50,158-64$

[24] Swain, M. (1995). Three Functions of Output in Second Language Learning. In Cook, G. \& Seidlhofer, B. (Eds) Principles \& Practice in Applied Linguistics,125-144, Oxford/Shanghai: Oxford University Press/Shanghai Foreign Language Education Press.

[25] Vandergrift, L. (1999). Facilitating second language listening comprehension: acquiring successful strategies. ELT Journal, 53(3), 168-76 
[26] Xia Jimei, Fen Pengpeng.(2006). Theories and Activities of the Foreign Language Teaching. Beijing: Higher Education Press.

[27] Xu Jingfen. (2006). The Theory and Practice of the Foreign language Teaching. Wuhan: Huazhong University of Science Press.

Wei Wu was born in Guangdong, China in 1976. She received her M.A. degree in English Language and Literature from Sun Yat-sen University, China in 2008.

She is currently a lecturer in the School of Foreign Languages, Guangzhou University, Guangdong, China. Her research interests include applied linguistics and college English teaching and research. 